\title{
Education for secondary prevention of foot ulcers in people with diabetes: a randomised controlled trial
}

\author{
N. B. Lincoln • K. A. Radford • F. L. Game • \\ W. J. Jeffcoate
}

Received: 14 April 2008 / Accepted: 2 July 2008 / Published online: 30 August 2008

(C) Springer-Verlag 2008

\begin{abstract}
Aims/hypothesis This observer-blind, randomised controlled trial was designed to determine the effect of a foot care education programme in the secondary prevention of foot ulcers. Methods People with newly healed foot ulcers attending one of three specialist clinics were allocated to receive either targeted, one-to-one education or usual care, using a computer-generated random allocation sequence that had been prepared in advance but which was concealed from the clinical researcher. The primary outcome was ulcer incidence at 12 months. Secondary outcomes were ulcer incidence at 6 months and incidence of amputation, mood (Hospital Anxiety and Depression Scale) and quality of life (Diabetic Foot Ulcer Scale) at 6 and 12 months. Protective foot care behaviours (Nottingham Assessment of Functional Footcare) were assessed at 12 months.

Results There were 87 (mean [SD] age 63.5 [12.1] years) patients in the intervention group and 85 control patients (mean [SD] age 64.9 [10.9] years). The groups were comparable at baseline. No significant differences $(p>$ 0.05 ) were observed between groups in ulcer incidence at either 6 months (intervention 30\%, control 21\%) or 12 months (intervention $41 \%$, control $41 \%$ ). Recommended foot care behaviours at 12 months were better in the
\end{abstract}

\footnotetext{
N. B. Lincoln

Institute of Work, Health and Organisations,

University of Nottingham,

Nottingham, UK

K. A. Radford · F. L. Game • W. J. Jeffcoate $(\bowtie)$

Foot Ulcer Trials Unit, Department of Diabetes and

Endocrinology, Nottingham University Hospitals Trust,

City Hospital Campus,

Nottingham NG5 1PB, UK

e-mail: wjeffcoate@futu.co.uk
}

intervention than in the control group $(p=0.03)$, but education had no significant $(p>0.05)$ effect on mood, quality of life or amputations.

Conclusions/interpretation Even though the intervention was associated with improved foot care behaviour, there was no evidence that this programme of targeted education was associated with clinical benefit in this population when compared with usual care. The usefulness and optimal delivery of education to such a high-risk group requires further evaluation.

Trial registration: ClinicalTrials.gov NCT00729456

Funding: Diabetes UK project grant RD02/0002535

Keywords Behaviour · Diabetes · Education · Foot $\cdot$ Ulcer
Abbreviations
DFS Diabetic Foot Scale
DFS-SF Short Form Diabetic Foot Scale
HADS Hospital Anxiety and Depression Scale
NAFF Nottingham Assessment of Functional Footcare

\section{Introduction}

Disease of the foot represents a major health problem in diabetes and is the source of enormous cost to healthcare services [1]. Healing is delayed and uncertain [2], and the incidence of amputation has been reported to be as high as $27 \%$ even in expert centres [3]. Since the options for specific therapy are limited [4], great emphasis is placed on prevention and on foot care education in particular [5-8]. While the importance of patient knowledge is undeniable, the effectiveness of education in reducing ulcer incidence has not been clearly demonstrated, as indicated by recent 
systematic [9] and non-systematic [10, 11] reviews. A reduced incidence of new foot ulcers has been shown when foot care education was included as part of an integrated package of diabetes care delivered to selected and relatively disadvantaged groups in the USA [12, 13], but has not been confirmed in other studies [14-19].

If education does have an impact on ulcer incidence, it might be expected to be most marked in patients at greatest risk, i.e. those who have had an ulcer before $[19,20]$. In a Swedish cohort study of 558 people managed between 1983 and 1990 ulcers recurred in 34,61 and $70 \%$ at 1,3 and 5 years, and major amputation in 3, 10 and $12 \%$ [21]. Of 226 patients with healed ulcers who were managed in the UK, $91(40.3 \%)$ developed a recurrent or new ulcer after a median 126 days (range 14-903) [22]. However, only one study of education has specifically targeted patients who had a previous lesion [23]. In that study, 203 patients admitted to hospital for a foot problem (ulcer, amputation, infection) were randomised to receive a single 1-h education session, including graphic images of foot problems, or to receive the usual care. While details of allocation concealment and blinding were not specified, the intervention group was reported to have a threefold, highly significant reduction in the incidence of both new ulcers and amputation within 13 months. If confirmed, this observation should inform clinical practice and structured foot care education should be adopted as part of the routine management of all patients with a healed foot lesion. The purpose of the present study was to seek to confirm those findings [23] by evaluating the provision of education in the secondary prevention of foot ulcers in patients attending three specialist footcare centres.

\section{Methods}

This study was funded by Diabetes UK and approved by the Local Research Ethics Committees of Nottingham and Southern Derbyshire, UK. Patients attending specialist foot clinics in Nottingham (Nottingham City Hospital and Queen's Medical Centre) and Derby (Derbyshire Royal Infirmary) were considered for inclusion in the study. Patients with diabetes and recently healed ulcers of the foot (on or below the malleoli) were eligible if they had remained ulcer-free for 28 days. Patients were excluded if they: lived in institutional care, had a documented history of dementia, had other serious medical problems, were nonEnglish-speaking and did not have an English-speaking carer, lived at a distance of more than 50 miles, were in another study, withheld consent or if they were members of the focus group involved in developing the education programme used in the study. Biographical details were recorded, including age, sex, educational level, social status and whether participants were living alone or with a partner or carer. Socio-economic groupings were established using the Standard Occupational Classification system [24] (I, professional; II, managerial and technical; III, skilled non-manual and manual; IV, partly skilled; V, unskilled occupations). Information was extracted from medical records on diabetes type and duration, diabetes control $\left(\mathrm{HbA}_{1 \mathrm{c}}\right.$ in the previous 3 months), nephropathy (serum creatinine $>120 \mu \mathrm{mol} / 1$ or persistent proteinuria) and retinopathy. Details of the previously healed ulcer were documented.

Baseline examination was conducted by a diabetes research nurse specialist or a research occupational therapist (K. A. Radford) trained in foot examination. The presence of sensory neuropathy was established using a $10 \mathrm{~g}$ monofilament on three sites (the plantar aspect of the hallux and under the 1st and 5th metatarsophalangeal joints). Pin prick sensation (Neurotips: Owen-Mumford, Woodstock, UK) was documented as being either present or absent on the dorsum of the foot. Vibration perception was recorded on the pulp of the hallux using a Neurosthesiometer (Horwell Scientific Laboratory Supplies, Nottingham, UK), with a recording of $\geq 25 \mathrm{~V}$ taken as abnormal. The presence of peripheral arterial disease was defined as having both pedal pulses missing. The Hospital Anxiety and Depression Scale (HADS) [25] was used as a measure of mood.

Participants were randomised 1:1 to receive either education or not by telephoning an independent randomisation centre which held a computer-generated random allocation sequence prepared in advance of the study. The sequence of random allocations was concealed from the researcher (K. A. Radford) recruiting participants. The intervention group received a single 1 -h education session within 4 weeks of randomisation. The education session was delivered to participants in their own homes, with or without their carers, by the researcher (K. A. Radford), who had been specifically trained. The content of the education session was based on the International Consensus on the Diabetic Foot [26], as well as the programme described by Malone and colleagues [23]. The content and wording of the educational material and the style of illustrations was also informed by discussion with a consumer focus group. The objective of the educational intervention was to prevent ulcer recurrence by lessening the impact of factors known to precipitate new ulcers. Participants were given a brief explanation of the principal causes of foot ulcers (impaired circulation, loss of sensation and secondary infection) $[27,28]$. Their feet were examined and any personal risk factors (such as deformity, ischaemia and neuropathy) were identified and explained. Shoes and insoles were examined for wear and tear and patterns of use and to determine whether choice of footwear constituted a particular risk for new ulceration. 
Participants were shown illustrations of foot lesions, since the use of illustrations was a feature of the intervention in the study reported by Malone and colleagues [23]. Illustrations included pictures of a foot with poor blood supply, signs of infection, a typical neuropathic ulcer, athlete's foot, Charcot's foot, a gangrenous toe and examples of accidental damage (burnt feet from dozing in front of a fire; a shoe sole penetrated by a nail). There was also a cartoon illustrating the development of a plantar neuropathic ulcer. Emphasis was placed on avoiding accidental damage by adopting preventive behaviours, such as checking the temperature of bath water, not walking barefoot and promoting foot health by washing, drying, moisturising and daily self-examination. Participants were also advised to contact the clinic at the first sign of any new or recurrent foot problem. Education sessions were supplemented by handouts to reinforce the information given. These handouts were those used routinely in the clinics and included information about the causes of foot ulcers (neuropathy, arteriopathy and infection), foot care and ways to reduce the likelihood of accidents. Patients were telephoned 4 weeks after the educational visit and a semistructured format used to discuss issues raised at the time of the home visit and to determine whether any points needed clarification or reinforcement. Those randomised to usual care received the same foot care leaflets but were otherwise managed according to usual practice. Such usual practice included no structured education and many patients were discharged to the care of their general practitioner, with or without input from a community podiatrist. Any education regarding prevention of ulcer recurrence was unstructured and opportunistic. The clinical care of patients in both groups was otherwise unaffected by the study. They were provided with regular podiatry and suitable orthoses when appropriate. Their overall medical care followed national UK guidelines and was supervised by GP, specialist clinic or both-according to individual circumstances.

Outcomes were assessed at 6 and 12 months after randomisation, by observers blind to the group allocation of the participants. The success of blinding was not assessed, but it was believed to be complete. The primary outcome measure was the occurrence of any new ulcers and was determined by medical and foot clinic records in the three hospitals supported by questionnaires sent to the patient. Outcomes at 12 months were also corroborated by writing to participants' general practitioners. Where a discrepancy between the patient report and medical records was found, the latter were re-checked and the probable cause of the discrepancy determined by blinded observers. A random sample of 20 cases in whom no recurrent foot problems were reported by the patient or GP, or recorded in the medical records was further cross-checked against community podiatry records by a blinded observer.
Secondary outcomes were assessed by questionnaires that were posted to participants with a reply-paid envelope. Those who did not return the questionnaires within 3 weeks were contacted by telephone and reminded. If questionnaires were returned incomplete, a blinded researcher also contacted the participants by telephone to ask them to complete the missing items. The outcome questionnaire included questions about the incidence of new ulcers and whether the patient had had any major or minor amputations. Participants were also asked to complete HADS as a measure of mood, which comprises seven items on anxiety and seven on depression and is suitable for people with physical illness. The Diabetic Foot Scale (DFS) [29] was included as a disease-specific measure of quality of life (although only items contained in the short form DFS [DFS-SF] [30] were analysed). This assesses the effect of foot problems on aspects of daily life, such as leisure, physical health, daily activities, emotions, family, friends and satisfaction. Participants were also asked to complete the Nottingham Assessment of Functional Footcare (NAFF) questionnaire [31] at 12 months, by which the frequency of 29 foot care behaviours was assessed. This questionnaire was developed specifically to assess foot care behaviour for the study, as no previous measure was identified as being suitable. The questionnaire had not been fully assessed at the time the study was started and was used only at 12 months. All questionnaires were scored by a researcher blind to the group allocation of participants and entered on the database. The relative risk was calculated for ulcers and amputations, using analysis by intention to treat. For secondary outcome questionnaires, the area under the curve was calculated only in returned questionnaires and compared using Mann-Whitney $U$ tests, with significance being set at $p=0.05$. To detect a reduction in 12-month incidence of new ulceration from 35 to $15 \%$ (two-sided, $80 \%, p=$ $0.05), 82$ participants were required in each group. Although sizeable, such a reduction would have been less than that reported by Malone and colleagues [23]. Results were analysed using SPSS version 14.

\section{Results}

During the 30 month recruitment period (April 2003 to September 2005), 1729 patients attended foot clinics in Nottingham (Nottingham City Hospital and Queen's Medical Centre) and at Derbyshire Royal Infirmary. Of these, 264 had had a foot ulcer that had recently healed, with 259 remaining healed and ulcer-free for 28 days. A total of 81 of these were excluded: five living in institutional care, one with documented dementia, one who died before giving consent, one who lived too far away, eleven with other serious medical problems, three in other studies, one who 
was involved in developing the education programme, four who were missed by error and 54 who refused consent. The recruitment and follow-up of participants is shown in Fig. 1.

Altogether, 178 patients gave informed consent and were randomised to the study. Six were withdrawn: one who was randomised twice by mistake, two who became ill before being seen (one in treatment group, one in control group), one who withdrew consent before being seen and one who was erroneously recruited because his previous ulcer had been above the malleoli. The remaining 172 were included in the analysis ( 85 control, 87 intervention group); their baseline characteristics are summarised in Table 1.

Patients recruited to the two groups were well matched at baseline. Ten participants died: five before the 6 month follow-up (two intervention, three control) and a further five by 12 months (four intervention, one control). Questionnaire completion rates are shown in Fig. 1. There were no significant differences in the occurrence of either new ulceration or amputation (Table 2). Only two of the amputations were major, one in each group.

A small number of answers was missing from the questionnaire replies. At 6 months there were six returned DFS-SF forms with questions unanswered. Three of these had one question unanswered and one had two unanswered.
In all four, the mean of all other responses in the subscale was inserted. In the other two cases, more than two replies were missing and these were not extrapolated. At 12 months, nine replies had missing items. The answer was provided by inserting the mean score in the six with one missing response and in the one with two missing responses. In the two other cases with more replies missing, these were not filled in by extrapolation. One participant left two questions unanswered on the HADS; these were replaced with the relevant mean scores. For the secondary outcomes, HADS and DFS-SF, summary measures of the area under the curve were calculated for each participant and compared using a Mann-Whitney $U$ test. These showed no significant differences between the groups on the HADS or DFS-SF $(p>0.05)$ (Table 3$)$. There were also no significant differences on any of the DFS-SF subscales.

A total of 26 participants failed to complete some of the questions in the NAFF. In 25 patients missing values were replaced by the mean for that individual. The other participant had omitted several questions and so these were not replaced. A Mann-Whitney $U$ test comparing the groups at 12 months showed that patients in the intervention group engaged in more of the recommended foot care behaviours, as assessed by the NAFF, than patients in the
Fig. 1 Flow diagram: recruitment and follow-up of participants

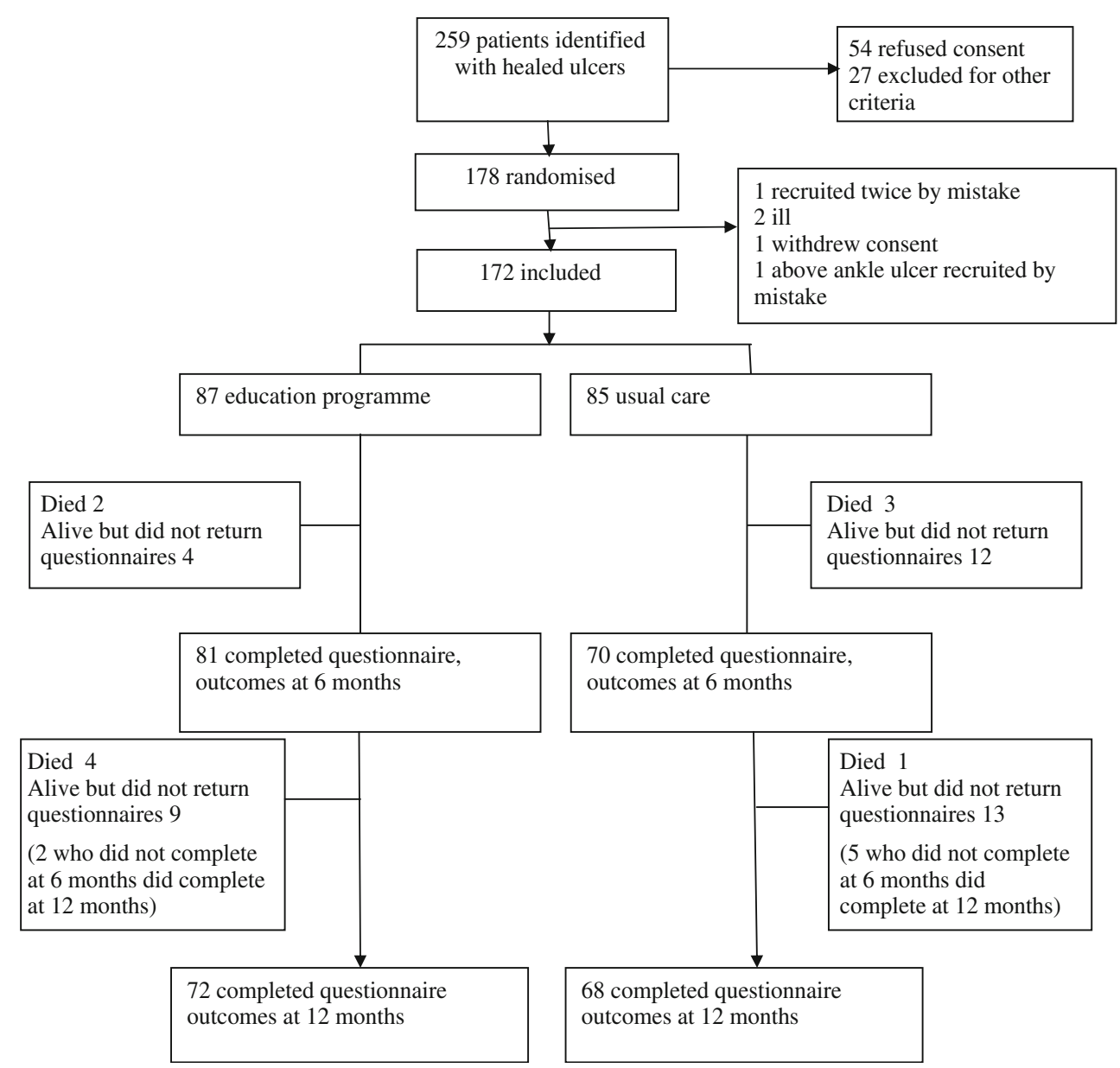


Table 1 Baseline characteristics of participants

\begin{tabular}{|c|c|c|}
\hline \multirow[t]{3}{*}{ Characteristics } & Intervention & Control \\
\hline & $n=87$ & $n=85$ \\
\hline & $\%$ & $n$ \\
\hline
\end{tabular}

\begin{tabular}{|c|c|c|c|c|}
\hline \multicolumn{5}{|l|}{ Sex } \\
\hline Male & 63 & 71 & 53 & 62 \\
\hline Female & 24 & 28 & 32 & 38 \\
\hline \multicolumn{5}{|l|}{ Centre } \\
\hline $\mathrm{CHN}$ & 49 & 56 & 54 & 63 \\
\hline QMC & 23 & 27 & 22 & 26 \\
\hline DRI & 15 & 17 & 9 & 11 \\
\hline \multicolumn{5}{|l|}{ Diabetes type } \\
\hline Type 1 & 23 & 26 & 16 & 19 \\
\hline Type 2 & 64 & 74 & 69 & 81 \\
\hline \multicolumn{5}{|l|}{ Retinopathy } \\
\hline Yes & 53 & 61 & 50 & 59 \\
\hline No & 34 & 39 & 35 & 41 \\
\hline \multicolumn{5}{|l|}{ Nephropathy } \\
\hline Yes & 25 & 29 & 19 & 22 \\
\hline No & 61 & 71 & 66 & 78 \\
\hline \multicolumn{5}{|l|}{ Ethnic origin } \\
\hline UK white & 83 & 95 & 82 & 96 \\
\hline Other & 4 & 5 & 3 & 4 \\
\hline \multicolumn{5}{|l|}{ Living } \\
\hline Alone & 18 & 21 & 14 & 16 \\
\hline With partner & 69 & 79 & 71 & 84 \\
\hline \multicolumn{5}{|l|}{ Currently working } \\
\hline Yes & 19 & 22 & 25 & 29 \\
\hline No & 68 & 78 & 60 & 70 \\
\hline \multicolumn{5}{|l|}{ Social class ${ }^{\mathrm{a}}$} \\
\hline 1 & 8 & 9 & 4 & 5 \\
\hline 2 & 15 & 17 & 19 & 22 \\
\hline 3 & 40 & 46 & 34 & 40 \\
\hline 4 & 18 & 21 & 20 & 24 \\
\hline 5 & 5 & 6 & 8 & 9 \\
\hline \multicolumn{5}{|l|}{ Site of ulcer } \\
\hline Forefoot & 70 & 81 & 67 & 80 \\
\hline Mid and hindfoot & 18 & 19 & 17 & 20 \\
\hline \multicolumn{5}{|c|}{ Previous amputation, other leg } \\
\hline None & 78 & 90 & 77 & 91 \\
\hline Minor & 6 & 7 & 5 & 6 \\
\hline Major & 3 & 3 & 3 & 3 \\
\hline \multicolumn{5}{|c|}{ Previous amputation, same leg } \\
\hline None & 70 & 80 & 75 & 88 \\
\hline Minor & 17 & 20 & 10 & 12 \\
\hline \multicolumn{5}{|l|}{$10 \mathrm{~g}$ monofilament } \\
\hline All three stimuli felt & 19 & 22 & 18 & 21 \\
\hline Only one or two felt & 27 & 31 & 31 & 36 \\
\hline None felt & 41 & 47 & 36 & 42 \\
\hline \multicolumn{5}{|l|}{ Neurotip } \\
\hline Felt & 55 & 65 & 54 & 64 \\
\hline Not felt & 30 & 35 & 31 & 36 \\
\hline \multicolumn{5}{|l|}{ Vibration perception } \\
\hline$\geq 25 \mathrm{~V}$ felt & 27 & 32 & 32 & 38 \\
\hline$\geq 25 \mathrm{~V}$ not felt & 57 & 68 & 52 & 62 \\
\hline \multicolumn{5}{|l|}{ Foot pulses } \\
\hline Both palpable & 30 & 35 & 33 & 39 \\
\hline
\end{tabular}

Table 1 (continued)

\begin{tabular}{|c|c|c|c|c|}
\hline \multirow[t]{3}{*}{ Characteristics } & \multirow{2}{*}{\multicolumn{2}{|c|}{$\begin{array}{l}\text { Intervention } \\
n=87\end{array}$}} & \multirow{2}{*}{\multicolumn{2}{|c|}{$\begin{array}{l}\text { Control } \\
n=85\end{array}$}} \\
\hline & & & & \\
\hline & $n$ & $\%$ & $n$ & $\%$ \\
\hline One palpable or both diminished & 39 & 45 & 28 & 33 \\
\hline Neither palpable & 17 & 20 & 24 & 28 \\
\hline \multicolumn{5}{|l|}{ Fitted footwear } \\
\hline Yes & 38 & 64 & 30 & 64 \\
\hline No & 21 & 36 & 17 & 36 \\
\hline
\end{tabular}

CHN City Hospital, Nottingham, DRI Derbyshire Royal Infirmary, $Q M C$ Queen's Medical Centre, Nottingham

${ }^{a}$ The Standard Occupation Classification system grades occupations as: I, professional; II, managerial and technical; skilled non-manual and manual; IV, partly-skilled; V, unskilled

control group: the median score in the intervention group was 42.0 compared with 38.7 in the controls $(p=0.03)$.

\section{Discussion}

We found no indication of any effect on the primary outcome, new ulceration, even though the intervention appeared to be associated with improved foot care behaviour in the intervention group. Although the study was powered to detect a sizeable reduction in recurrence, this was less than the threefold reduction reported by Malone et al. [23], on whose data our sample size calculation was based. As it happens, the incidence of new ulceration in the two groups was identical, at $41 \%$, without even a trend towards benefit in the intervention group. Similarly, no indication of an effect on the incidence of major or minor amputation, or on mood or on quality of life was seen.

The primary outcome measure was the incidence of new ulceration at any site on either foot and was determined by examination of medical records, supplemented by information derived from questionnaires sent to the patients and to their GPs. Occasional discrepancies concerning ulcer occurrence and amputation were found between the medical records and the patient reports, but after reviewing the medical records, these were explained by errors in recall (with patients reporting ulcers and amputations which had actually occurred before the date of randomisation), by occasional confusion between ulcers of the foot and of the leg and by the known tendency of some patients not to acknowledge an ulcer which they have actually had.

Our findings are in contrast to those of Malone et al. [23], who found that education led to a major reduction in ulcer incidence and amputation within 13 months. Possible reasons for the difference may be that the earlier study was 
Table 2 Frequency of new ulceration and of amputation

\begin{tabular}{|c|c|c|c|c|c|c|}
\hline \multirow[t]{3}{*}{ Outcome } & \multirow{2}{*}{\multicolumn{2}{|c|}{$\begin{array}{l}\text { Intervention } \\
n=87\end{array}$}} & \multirow{2}{*}{\multicolumn{2}{|c|}{$\begin{array}{l}\text { Control } \\
n=85\end{array}$}} & \multicolumn{2}{|c|}{ Comparison } \\
\hline & & & & & \multirow[b]{2}{*}{$\mathrm{RR}^{\mathrm{a}}$} & \multirow[b]{2}{*}{$95 \% \mathrm{CI}$} \\
\hline & $n$ & $\%$ & $n$ & $\%$ & & \\
\hline \multicolumn{7}{|c|}{ Outcome at 6 months } \\
\hline Foot ulcer & 26 & 30 & 18 & 21 & & \\
\hline No foot ulcer & 61 & 70 & 67 & 79 & 0.890 & $0.746-1.061$ \\
\hline Amputation & 3 & 3 & 0 & 0 & & \\
\hline No amputation & 84 & 96 & 85 & 100 & 0.966 & $0.928-1.005$ \\
\hline \multicolumn{7}{|c|}{ Outcome at 12 months } \\
\hline Foot ulcer & 36 & 41 & 35 & 41 & & \\
\hline No foot ulcer & 51 & 59 & 50 & 59 & 0.997 & $0.776-1.280$ \\
\hline Amputation & 9 & 10 & 9 & 11 & & \\
\hline No amputation & 78 & 90 & 76 & 89 & 1.003 & $0.905-1.111$ \\
\hline
\end{tabular}

${ }^{a}$ Relative risk or risk ratio expressed as the ratio of the estimated risk of a good outcome (no ulcer or no amputation) in the intervention group to that in the control group and we had no reason to suspect a difference between groups, it is possible that these observations reflect chance differences between groups at baseline. It should also be noted that the previously reported internal consistency of the NAFF was only just adequate [31], but there was no alternative measure available.

The educational intervention was designed to be systematic and yet both personalised and acceptable to the patient. It was delivered by the same healthcare professional and was followed after 1 month by a phone call from the same person, in which the principal issues raised at the earlier visit were reinforced. While it is possible that a more intensive programme might have led to greater benefit, it is difficult to envisage that such an intensive programme could ever be incorporated into routine management without major investment. Moreover, the intervention adopted in this study was associated with an apparent improvement in reported foot care behaviour in the intervention group. Differences observed consisted of the intervention group having higher scores in certain foot care items, such as checking shoes before putting them on, daily washing and the use of moisturising cream. No differences were reported for items concerned with choice of footwear

Table 3 Comparison of groups on secondary outcomes

\begin{tabular}{|c|c|c|c|c|c|c|c|c|c|}
\hline \multirow[t]{2}{*}{ Outcome } & \multicolumn{4}{|c|}{ Intervention } & \multicolumn{4}{|c|}{ Control } & \multirow{2}{*}{$\begin{array}{l}\text { Comparison }^{\mathrm{a}} \\
p \text { value }\end{array}$} \\
\hline & $n$ & $\begin{array}{l}\text { Baseline } \\
\text { Median }\end{array}$ & $\begin{array}{l}6 \text { months } \\
\text { Median }\end{array}$ & $\begin{array}{l}12 \text { months } \\
\text { Median }\end{array}$ & $n$ & $\begin{array}{l}\text { Baseline } \\
\text { Median }\end{array}$ & $\begin{array}{l}6 \text { months } \\
\text { Median }\end{array}$ & $\begin{array}{l}12 \text { months } \\
\text { Median }\end{array}$ & \\
\hline DFS-SF & 67 & NA & 63.7 & 67.2 & 61 & NA & 69.6 & 59.3 & 0.87 \\
\hline HAD-A & 65 & 5 & 5 & 5 & 60 & 6 & 5 & 6 & 0.70 \\
\hline HAD-D & 65 & 4 & 5 & 4 & 60 & 5 & 5 & 5 & 0.53 \\
\hline NAFF & 72 & NA & NA & 42.0 & 66 & NA & NA & 38.7 & 0.03 \\
\hline
\end{tabular}

Higher scores indicate better quality of life (DFS-SF) and foot care behaviour (NAFF) but lower mood (HADS)

${ }^{a}$ Using Mann-Whitney $U$ test. Area under the curve was compared for DFS-SF ( 6 and 12 months) and HADS scales (baseline, 6 and 12 months). The numbers assessed are from patients who returned questionnaire on both (DFS-SF) and all three (HADS) occasions

$H A D-A$ HAD scale, anxiety, HAD-D HAD scale, depression, $N A$ not administered 
or with prevention of accidental damage, although it is known that accidents and factors relating to footwear are most often implicated in the cause of new ulcers $[29,30]$. This failure to change aspects of behaviour most likely to be associated with increased risk is important and suggests that even though these items were specifically targeted in the educational interview, they might need even greater emphasis in any future work. There were no significant effects of the intervention on mood or quality of life. The sample size was also relatively small for studies on quality of life and determined on the basis of the primary endpoint, so it is possible that a real effect was missed.

Overall, the results of this study suggest that a targeted programme of education for people with foot ulcers that had been managed in specialist foot clinics in UK and had healed, improved some aspects of foot care behaviour but had no effect on the incidence of new ulceration at either 6 or 12 months. There is therefore no evidence to justify the adoption of such a programme of education to reduce new ulcer incidence in such a population. Paradoxically, it is possible that an education programme may fail to reduce ulcer incidence in a very high-risk population such as this simply because the influence of the factors that put them at risk may be far greater than can be offset by any change in foot care behaviour. But although we have been unable to document a benefit from the particular intervention chosen for study, we feel that every effort should continue to be made to ensure that patients with healed ulcers reduce riskassociated behaviour as much as possible. It is possible that this could be achieved by a more intensive programme of education, but until the effectiveness of such a programme has been shown, educational effort must necessarily be unstructured and targeted at the needs of each individual.

It is relevant that our failure to observe a fall in ulcer incidence echoes the observations of McCabe and colleagues in a similar, but only partly randomised study of a population at high risk in UK [14]. This group, however, did observe that the incidence of amputation was lower in their intervention group and one interpretation of this finding is that the education programme may encourage a patient with a new ulcer to seek expert help earlier and that this may lead to an improved outcome. If so, this might also explain some of the benefit observed by Malone and colleagues [23], but not observed in the present study because the incidence of major amputation was very low in both our study groups. This possible indirect benefit of patient education in improving the outcome of new ulceration as much as its incidence needs further study.

Acknowledgements We thank Diabetes UK for supporting this study (grant RD02/0002535). We also thank V. Savage, B. Kirk, S. Stevenson, M. Smith, P. Ince and A. Musgrove for their considerable help in recruiting patients to the study, data entry and checking outcome measures. Thanks also to S. Page and colleagues at the
Queen's Medical Centre, Nottingham, and P. Amin and colleagues at Derbyshire Royal Infirmary for enabling us to study their patients. We are particularly grateful to S. Lewis for statistical advice.

Duality of interest The authors declare that there is no duality of interest associated with this manuscript.

\section{References}

1. Boulton AJ, Vileikyte L, Ragnarson-Tennvall G, Apelqvist J (2005) The global burden of diabetic foot disease. Lancet 366:1719-1724

2. Treece KA, Macfarlane RM, Pound N, Game FL, Jeffcoate WJ (2004) Validation of a system of foot ulcer classification in diabetes mellitus. Diabet Med 21:987-991

3. Armstrong DG, Lavery LA, Harkless LB (1998) Validation of a diabetic wound classification system. The contribution of depth, infection, and ischemia to risk of amputation. Diabetes Care 21:855-859

4. Cavanagh PR, Lipsky BA, Bradbury AW, Botek G (2005) Treatment for diabetic foot ulcers. Lancet 366:1725-1735

5. American Diabetes Association (2007) Standards of medical care in diabetes - 2007. Diabetes Care 30(Suppl 1):S4-S41

6. National Institute for Health and Clinical Excellence (2004) Key criteria that a structured education programme should meet to fulfil the NICE requirements. Available from http://nice.org.uk/ CG10, accessed 14 July 2008

7. National Institute for Clinical Excellence (2003) Guidance on the use of patient-education models for diabetes. Technology Appraisal 60. Available from http://www.nice.org.uk/download.aspx? $\mathrm{o}=$ TA060guidance, accessed 29 November 2007

8. Scottish Intercollegiate Guidelines Network, Management of diabetic foot disease. Available from http://www.sign.ac.uk/guide lines/fulltext/55/section7.html, accessed 29 November 2007

9. Valk GD, Kriegsman DM, Assendelft WJ (2005) Patient education for preventing diabetic foot ulceration (Cochrane Review). The Cochrane Library, Issue 2, Oxford, Update Software

10. Radford K, Chipchase S, Jeffcoate W (2005) Education in the management of the foot in diabetes. In: Boulton AJM, Cavanagh PR, Rayman G (eds) The foot in diabetes. 4th edn. Wiley, London, pp 143-158

11. Singh N, Armstrong DG, Lipsky BA (2005) Preventing foot ulcers in patients with diabetes. JAMA 293:217-228

12. Litzelman DK, Slemenda CW, Langeveld CD et al (1993) Reduction of lower extremity clinical abnormalities in patients with non-insulindependent diabetes mellitus. Ann Intern Med 119:36-41

13. Rith-Najarian S, Branchaud C, Beaulieu O, Gohdes D, Simonson G, Mazze R (1998) Reducing lower-extremity amputations due to diabetes: application of the staged diabetes management approach in a primary care setting. J Fam Pract 47:127-132

14. McCabe CJ, Stevenson RC, Dolan AM (1998) Evaluation of a diabetic foot screening and protection programme. Diabet Med $15: 80-84$

15. Rettig BA, Shrauger DG, Recker RR, Gallagher TF, Wiltse H (1996) A randomized study of the effects of a home diabetes education program. Diabetes Care 9:173-178

16. Bloomgarden ZT, Karmally W, Metzger MJ et al (1997) Randomized, controlled trial of diabetic patient education: improved knowledge without improved metabolic status. Diabetes Care 10:263-272

17. Hamalainen H, Ronnemaa T, Toikka T, Liukkonen I (1998) Longterm effects of one year of intensified podiatric activities on footcare knowledge and self-care habits in patients with diabetes. Diabetes Educ 24:734-740 
18. Ronnemaa T, Hamalainen H, Toikka T, Liukkonen I (1997) Evaluation of the impact of podiatrist care in the primary prevention of foot problems in diabetic subjects. Diabetes Care 20:1833-1837

19. Peters EJ, Lavery LA (2001) Effectiveness of the diabetic foot risk classification system of the International Working Group on the Diabetic Foot. Diabetes Care 24:1442-1447

20. Leese GP, Reid F, Green V et al (2005) Predicting foot ulceration in diabetes: validation of a clinical tool in population-based study. Int J Clin Pract 60:541-545

21. Apelqvist J, Larsson J, Agardh C-D (1993) Long-term prognosis for diabetic patients with foot ulcers. J Intern Med 233:485-491

22. Pound N, Chipchase S, Treece K, Game F, Jeffcoate W (2005) Ulcer-free survival following management of foot ulcers in diabetes. Diabet Med 22:1306-1309

23. Malone JM, Snyder M, Anderson G, Bernhard VM, Holloway GA, Bunt TJ (1989) Prevention of amputation by diabetic education. Am J Surg 158:520-524

24. Office for Population Censuses and Surveys (1991) Standard occupational classification system. HMSO, London
25. Zigmond AS, Snaith RP (1983) The hospital anxiety and depression scale. Acta Psychiatr Scand 67:361-370

26. International Consensus on the Diabetic Foot. International Working Group on the Diabetic Foot, 2003. Available from www.iwgdf/org, accessed 14 July 2008

27. Macfarlane RM, Jeffcoate WJ (1997) Factors contributing to the presentation of diabetic foot ulcers. Diabet Med 14:867-870

28. Pecoraro RE, Reiber GE, Burgess EM (1980) Pathways to diabetic limb amputation. Basis for prevention. Diabetes Care 13:513-521

29. Abetz L, Sutton M, Brady L, McNulty P, Gagnon D (2002) The Diabetic Foot Ulcer Scale (DFS): a quality of life instrument for use in clinical trials. Pract Diabetes Int 19:167-175

30. Bann CM, Fehnel SE, Gagnon DD (2003) Development and validation of the Diabetic Foot Ulcer Scale-Short Form (DFS-SF). Pharmacoeconomics 21:1277-1290

31. Lincoln NB, Jeffcoate WJ, Ince P, Smith M, Radford KA (2007) Validation of a new measure of protective footcare behaviour: the Nottingham Assessment of Functional Footcare (NAFF). Pract Diabetes Int 24:207-211 